Doc. dr. Fehim Rošić

\title{
POJAM O SEBI KAO PEDAGOŠKA KATEGORIJA - OSNOVNE ODREDNICE I ZNAČENJE
}

Sažetak

U složenoj interakciji između individue $i$ okoline, tokom razvoja i formiranja ličnosti, razvija se i formira $i$ vlastita slika o sebi ili pojam o sebi, kao posebna dimenzija osobnosti. U određivanju $i$ definiranju pojma o sebi, tokom razvoja teorijske misli, mogu se uočiti dva pristupa: tradicionalni, koji razlikuje egzistencijalni $i$ empirijski aspekt ovog pojma, i savremeni, koji ovaj pojam definira kao sistem tri međusobno povezna procesa: svijest o sebi, samoevaluacija i samoregulacija. Pojam o sebi usko je povezan sa percepcijom $i$ autopercepcijom, odnosno, doživljavanjem odnosa drugih prema individui i doživljavanjem samoga sebe.

$S$ obzirom da pojam o sebi značajno utiče na ukupno funkcioniranje individue, te da se razvija i formira tokom složenog procesa međusobnog djelovanja i uticaja različitih odgojnih faktora, ovaj pojam, pored psihološke, ima i veoma značajnu pedagošku dimenziju i značenje.

Uvod

Čovjek tokom cijelog života, a posebno u periodu svoga razvoja i sazrijevanja, prolazi kroz vrlo kompleksan proces socijalnog učenja, u kojem istovremeno djeluje velik broj faktora, pa je tako svaka individua tokom svog cjelokupnog života i funkcionisanja u stalnoj interakciji sa svojom okolinom. Taj proces je permanentan i obostran, a njegovi efekti i konzekvence javljaju se i kod individue i kod njene okoline. Efekti ovih interakcijskih odnosa mogu povoljno uticati na čovjeka, mogu podsticati njegov razvoj, pomoći njegovoj integraciji i prilagođavanju okolini, ali mogu imati i štetno djelovanje na njegov razvoj, uspješnost funkcionisanja i psihički život.

Kroz ovaj proces učenja čovjek usvaja znanja, razvija svoje sposobnosti i formira stavove o vanjskom svijetu koji ga okružuje, ali 
i o sebi samome, što determiniše njegovo ponašanje i ukupno funkcionisanje. $U$ toj interakciji individue $\mathrm{i}$ okoline razvija se $\mathrm{i}$ formira vlastita slika o sebi, samopoimanje, samosvijest, kao posebna dimenzija osobnosti. U periodu djetinjstva i mladosti, uporedo sa spoznavanjem svijeta oko sebe, dijete samo sebi postavlja brojna pitanja i traži odgovore na njih, u smislu: ko sam ja zapravo, šta mislim o sebi, koje su moje mogućnosti i sl. Ta pitanja se uglavnom odnose na osjećaj, doživljaj i percepciju ličnog identiteta i samopoimanja sposobnosti da li osoba nešto može ili ne može postići ili učiniti.

Djeca, ali i odrasli također, traže odgovore i na brojna druga pitanja koja bi im trebala pomoći da sami sebe bolje razumiju. Ovo pitanje je posebno značajno u adolescenciji, jer je «osnovni događaj adolescencije otkrivanje sebe kao bića određenog svijetom drugih $\mathrm{u}$ svim svojim vidovima». ${ }^{1}$ Značaj ovog aspekta razvoja bio je podsticajan i izazovan za brojne autore da počnu istraživati i proučavati pojam o sebi, kao važno psihološko i pedagoško pitanje i fenomen.

U određivanju i definisanju pojma o sebi teoretičari su koristili i primjenjivali različite pristupe, modele $\mathrm{i}$ obrasce. Tradicionalni pristup razlikuje dva ključna aspekta ili komponente ovog pojma:

a) egzistencijalni ili «ja» - aspekt: Ovaj aspekt pojma o sebi odnosi se na subjektivni doživljaj vlastitog postojanja, a obuhvata osjećaj i svijest o ličnom identitetu, o svojim sposobnostima i o svom postojanju tokom vremena.

b) empirijski ili «mene» - aspekt: Ova komponenta pojma o sebi se odnosi na objektivno vlastito doživljavanje i razumijevanje svojih ličnih obilježja - fizički izgled, socijalni status, osobine ličnosti, kognitivne sposobnosti i dr.

Prema Dejmonu i Hartu (Damon i Hart) ove dvije sastavne komponente pojma o sebi određuju našu svijest o tome ko smo i kakvi smo, i značajno utiču na razvoj naše ličnosti i naše ukupno funkcionisanje.

\footnotetext{
${ }^{1}$ Kuburić Z.: Porodica i psihičko zdravlje djece, «Čigoja štampa», Beograd, 2001, str. 46.

2 Vasta R., Haith M.M., Miller A.S.: Dječja psihologija, «Naklada Slap», Jastrebarsko, 1998, str. 488.
} 
Savremeni pristup u proučavanju pojma o sebi određuje i definiše ovaj pojam kao sistem triju međusobno povezanih procesa:

1. znanje o sebi ili svijest o sebi: U pojmu o sebi, kao sistemu, ovaj proces se odnosi na ono što individua zna o samom sebi. To je kognitivni aspekt ovog pojma, a obuhvata znanje o samom sebi, te kako i kada je to saznanje stečeno.

2. samovrednovanje (samoevaluacija): Ovo je dio pojma o sebi koji se odnosi na ono što osoba misli o sebi i svojim sposobnostima. Brojni faktori utiču na naše mišljenje o sebi, a to dobrim dijelom determiniše naše ponašanje, naš odnos prema sebi, prema drugima i uopće naše ukupno funkcionisanje.

3. samoregulacija: Ovaj proces, kao sastavna komponenta pojma o sebi, odnosi se na samokontrolu, kako je stičemo, koje varijable utiču na taj proces i kako pojam o sebi učestvuje u regulisanju i kontroli našeg ponašanja.

U određivanju i definisanju pojma o sebi postoje i koriste se različiti pristupi i terminološka određenja. Neki autori (Kreč $i$ Kračfild) pod tim pojmom podrazumijevaju poimanje sopstvenog JA (self-conception), kod drugih (Presi, Robins, Horoks) taj pojam obuhvaća samoprocjenu (self-estimate), a za Olporta pojam o sebi predstavlja, u osnovi, svijest o svijesti (consiciousness of the consiciousness), odnosno, da smo svjesni sami sebe i svoje svjesnosti.

Don Dinkmajer iznosi da je Raimy, u svojoj doktorskoj tezi «The Self Concept as a Factor in Counseling and Personality Organization», još 1943. godine prvi definisao pojam o sebi kao «više ili manje organizovan perceptualni činilac koji rezultira iz sadašnje i prošle samoopservacije /.../. To je ono što ličnost veruje o sebi samoj. Slika o sebi je mapa koju svaka ličnost konsultuje u cilju razumevanja same sebe, a posebno u situacijama kada nastupaju krize ili se čini neki izbor u životu.» ${ }^{3}$ Ingliš - Ingliš navode da je slika o sebi «kako čovek zamišlja sebe da jeste. Ovo nije neposredno samoposmatrani objekat, već je složeni pojam o sopstvenoj ličnosti, karakteru, statusu,

${ }^{3}$ Mandić P., Radovanović I., Mandić D.: Uvod u opštu informatičku pedagogiju, Učiteljski fakultet, Beograd, 2000, str. 190. 
telu i telesnoj pojavi itd. Ova zamišljena slika može da se znatno razlikuje od objektivnog činjeničnog stanja.»» ${ }^{4}$

Kreč i Kračfild (D. Krech, R. Crutchfield), analizirajući svijest o sebi ili poimanje sopstvenog «ja» ističu da «svaki pojedinac opaža da je on određen 'tip ljudi' koji ima izvesne crte ličnosti, navike, karakteristične načine ponašanja; da poseduje izvesne sposobnosti, veštine, znanja; da ima različita uverenja, vrednosti, stavove; da je usmeren različitim ciljevima i aspiracijama. On takođe opaža svoje odnose sa sredinom - to jest, kakve objekte poseduje, kakvoj socijalnoj grupi pripada, kakav mu je društveni status i kakve su mu društvene uloge, kako izgleda u očima drugih ljudi.» ${ }^{5}$ Prema ovim autorima struktura naše svijesti o sebi ili poimanja našeg sopstvenog «ja» je slojevita, gdje se mogu razlikovati:

a) centralni $i$ periferni slojevi: Svaki pojedinac osjeća neke dijelove svoga «ja» kao bliže suštinskoj biti njegovog «ja», a duge u izvjesnoj mjeri kao manje bitne ili periferne. Presjek te strukture mogao bi se ilustrativno uporediti sa poprečnim presjekom stabla drveta ili glavice luka: ako od perifernih koncentričnih slojeva ili godova idemo prema unutrašnjosti, približavamo se centralnim slojevima - svaki od slojeva ima svoju poziciju i udaljenost od srži.

b) «viši $i$ «niži»» slojevi: Sa aspekta samovrednovanja mi neke dijelove svoga «ja» doživljavamo bolje, vrednije i poželjnije od drugih. Ova vertikalna hijerarhija u doživljavanju vlastitih svojstava i vrijednosti formira se pod snažnim uticajem ukupne društvene sredine i odražava religioznu i kulturnu klimu pojedinih historijskih razdoblja: u antičkoj Grčkoj duša, duh i tijelo predstavljali su silazni slijed u hijerarhiji poželjnih svojstava čovjekovog «ja», u drugim razdobljima se govorilo «o životinjskoj prirodi nasuprot spiritualnoj prirodi, slepim instinktima nasuprot racionalnoj misli, zlim impulsima nasuprot dobrim impulsima». ${ }^{6}$

\footnotetext{
${ }^{4}$ Ingliš H.B., Ingliš A.C.: Obuhvatni rečnik psiholoških i psihoanalitičkih pojmova, Beograd, 1972, str. 501.

${ }^{5}$ Kreč D., Kračfild R.: Elementi psihologije, «Naučna knjiga», Beograd, 1980, str. 212.

${ }^{6}$ Kreč D., Kračfild R.: Elementi psihologije, «Naučna knjiga», Beograd, 1980, str. 213.
} 
Prema jednom od najopsežnijih pregleda ranijih istraživanja pojma o sebi koji je dala Vili (Wylie R. C. 1979), ova istraživanja se mogu klasifikovati u tri grupe:

c) istraživanja provedena $\mathrm{s}$ ciljem da provjere mjerne instrumenate iz ove oblasti,

d) istraživanja povezanosti pojma o sebi sa drugim konstruktima, kao što su percepcija odnosa sa roditeljima, lokus kontrole, samoefikasnost, anksioznost i dr.,

e) longitudinalna i transverzalna istraživanja koja se odnose na period adolescencije. ${ }^{7}$

U istraživanju socijalne percepcije Sirs (R. R. Sears) 50-tih godina prošlog vijeka ispitivao je jedan vid autopercepcije koji se odnosio na opažanje sopstvenih crta ličnosti. Ispitanici su imali zadatak da ocijene sebe u pogledu neurednosti, tvrdoglavosti, škrtosti $i$ stidljivosti, kao socijalno nepoželjnih crta. Kao kriterij tačnosti autopercepcije uzimao je stepen slaganja vlastite samoprocjene i procjene koju su davali drugi subjekti istraživanja. Istraživanje je pokazalo da se naša slika o sebi razlikuje u odnosu na sliku koju o nama imaju drugi. Lipi, Polanski $i$ Rosen su (1952) ispitivali autopercepciju slijedećih dimenzija slike o sebi: sposobnost za borbu, nezavisnost od odraslih, omiljenost i utišaj u grupi, a Ausubel i Šift (1955) autopercepciju socioempatijske sposobnosti, čiji je jedan vid sposobnost autopercepcije sopstvenog socijalnog statusa. Vera Smiljanić-Čolanović je kod nas 1972. godine provela značajno istraživanje autopercepcije inteligencije i socijalne prihvaćenosti. ${ }^{8}$

Ono što mi znamo, osjećamo i mislimo o sebi razlikuje se od onog kako nas drugi vide. Taj odnos slike o sebi i slike o nama kod drugih je vrlo složen i značajno utiče na naše ukupno ponašanje i funkcionisanje. U trajnoj interakciji između nas i ukupne društvene sredine mi neprekidno primamo od drugih neke informacije o sebi, ali ih istovremeno i upućujemo drugima i tako, zapravo, komuniciramo. Jedan od načina prikazivanja značaja i uticaja te međuzavisnosti u komunikaciji je tzv. Joharijev kvadrat. (Slika br.1)

\footnotetext{
${ }^{7}$ Kuburić Z.: Porodica i psihičko zdravlje djece, «Čigoja štampa», Beograd, 2001, str. 47.

${ }^{8}$ Smiljanić - Čolanović V.: Sociometrija i ispitivanje socijalne percepcije, «Zavod za udžbenike i nastavna sredstva Srbije», Beograd, 1973, str. 39.

${ }^{9}$ Pregrad J. (ured.): Stres, trauma, oporavak, «D.P.P.», Zagreb, 1996, str. 24.
} 


\section{DRUGI O MENI}

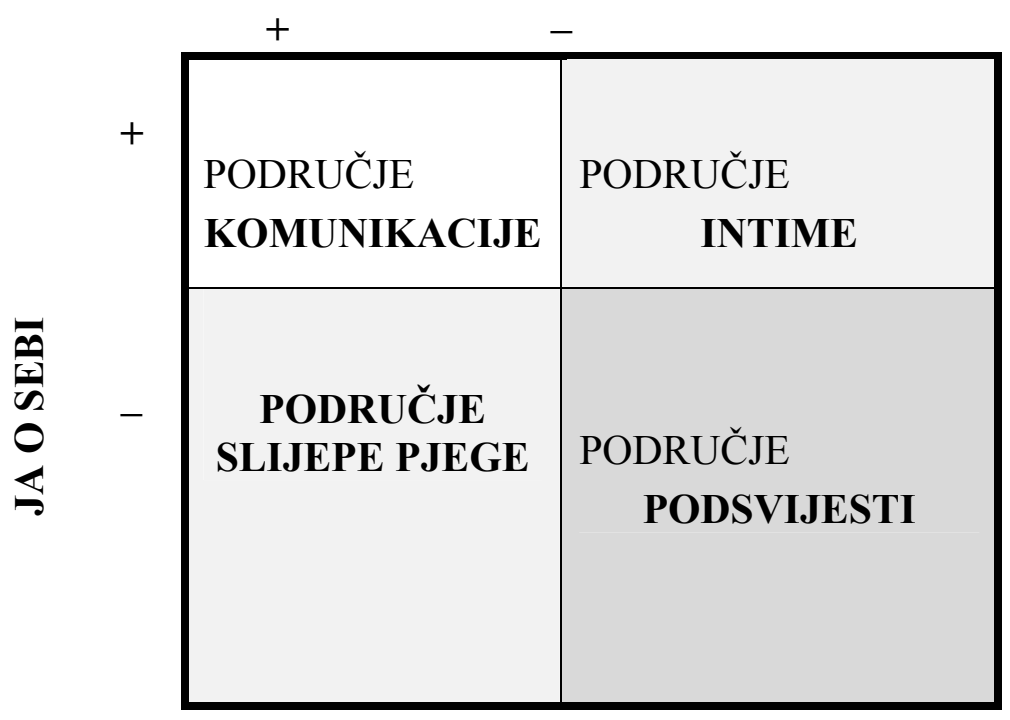

\section{Slika br. 1: Joharijev kvadrat}

Jedna stranica kvadrata predstavlja ono što mi o sebi znamo, osjećamo, mislimo i primjećujemo, a druga predstavlja ono kako nas drugi vide, šta o nama znaju i šta o nama misle. Dijelovi ovih stranica označeni sa «+» i «-» predstavljaju ono što mi o sebi, ili drugi o nama, znamo ili ne znamo, primjećujemo ili neprimjećujemo i sl. Na taj način se komunikacijski prostor svake osobe može podijeliti $u$ četiri područja:

a) područje komunikacije: Ovo područje komunikacije obuhvata izmjenu informacija koje mi o sebi znamo i koje drugi znaju o nama. Kada se osobe ne poznaju, ovo područje komunikacije je malo, a povećava se našim daljim saznanjima o sebi i saznanjima našeg sagovornika o nama.

b) područje intime: Ovo je ono područje u kojem ja o sebi znam sve ili većinu stvari, a drugi o tome ne znaju ništa ili ne znaju dovoljno. Ovo je područje, zapravo, područje našeg unutrašnjeg dijaloga, a kad su dvije osobe duže u interakciji, ovo se područje širi. 
c) područje slijepe pjege: U našem samopoimanju postoji dosta toga što mi kod sebe ne primjećujemo ili ne vidimo, o čemu ne znamo, a drugi to zapažaju i vide. Taj dio naše slike o sebi je nerealan, mi o sebi mislimo drukčije nego što nas drugi doživljavaju i vide.

d) podsvjesno područje: Ovo je područje naše ličnosti koje nije dostupno našoj svijesti, a ni drugi o tome ništa ne znaju.

Iako je Joharijev kvadrat uglavnom vezan za pitanja komunikacije, on ipak pruža značajne informacije o pojmu o sebi i njegovoj složenoj povezanosti sa drugim aspektima našeg ponašanja i doživljavanja. Naime, prema Midu (Mead G. H., 1934) mi smo skloni «da vidimo sebe onako kako su nas 'značajni drugi' videli, i ako su nas naši roditelji, kao najznačajniji 'drugi' odbacivali kao decu, mi smo skloni da definišemo sebe kao nezaslužne ljubavi, čak i kao bezvredna i neadekvatna ljudska bića». ${ }^{10}$

Naša procjena, doživljavanje i uvjerenje o tome kako nas drugi vide, kako prema nama postupaju i kako to manifestuju, značajno utiče na razvoj našeg poimanja sebe, za razvoj naše slike ili pojma o sebi. Erikson je isticao da se uobličavanje našeg identiteta odvija «kroz proces simultanog razmišljanja i posmatranja, proces koji se odigrava na svim nivoima funkcionisanja uma, kroz koji jedinka procjenjuje sebe u svetlu onoga što ona percipira kao način na koji nju procenjuju drugi». ${ }^{11}$

Poseban značaj u razvoju i formiranju pojma o sebi i ličnosti u cjelini, ne zanemarujući faktore šireg društvenog okruženja, ima porodica. U dječijem razvoju je vrlo bitna uloga značajnih odraslih osoba: roditelja $\mathrm{i}$ rodbine, pogotovo u predškolskom i mlađem školskom periodu, kada ove osobe predstavljaju skoro jedinu osnovu za dječije prosuđivanje vlastitog ponašanja i reagovanja. Kroz svoju aktivnost na upoznavanju i istraživanju sredine kod djeteta se formira povratna sprega, na osnovu koje ono vrednuje svoja iskustva i tako formira i introjicira stavove i vrijednosti o ambijentnoj realnosti, ali i o samome sebi.

\footnotetext{
${ }^{10}$ Kuburić Z.: Porodica i psihičko zdravlje djece, «Čigoja štampa», Beograd, 2001, str. 25.

${ }^{11}$ Erikson E.: Omladina, kriza, identifikacija, «Pobjeda», Titograd, 1976, str. 17.
} 


\section{Literatura:}

1. Ackerman, N.: Psihodinamika porodičnog života, dijagnoza $i$ lečenje porodičnih odnosa, «Grafički zavod», Titograd, 1966.

2. Adžbaba - Gajanović, N.: Psihički razvoj djeteta $i$ vaspitanje, «Svjetlost», Sarajevo, 1982.

3. Allport, G.: Sklop i razvoj ličnosti, «Kultura», Beograd, 1969.

4. Belsky, J., Lerner, R., Spanier, G.: The Child in the Family, Reradin, MA, Adison - Wesley, 1984.

5. Berdjajev, N.: Samospoznaja, Novi Sad, 1987.

6. Bergant, M.: Vaspitni zadaci porodice nekad $i$ sad, Pedagogija I i II, Beograd, 1979.

7. Bezinović P.: Percepcija vlastite kompetentnosti - moguća hijerarhijska organizacija, «Društvo psihologa Hrvatske», Zagreb, 1990.

8. Bronfenbrener, U.: Ekologija ljudskog razvoja, «Zavod za udžbenike i nastavna sredstva», Beograd, 1997.

9. Daně̌, V.: Dijete, vanjski svijet i psihički poremećaji, «Dom štampe», Zenica, 2003,

10. Demarin, J., Ogrizović, M.:Odnos roditelja prema djeci, «Naprijed», Zagreb, 1954.

11. Ekerman, N.: Psihodinamika porodičnog života, «Grafički zavod», Titograd, 1966.

12. Erikson E.: Omladina, kriza, identifikacija, «Pobjeda», Titograd, 1976.

13. Frojd, A.: Normalnost i patologija u djetinjstvu, «Zavod za udžbenike i nastavna sredstva», Beograd, 2000.

14. Fromm, E.: Autoritet i porodica, «Naprijed», Zagreb, 1980.

15. Herlok, E.: Razvoj deteta, «Zavod za udžbenike i nastavna sredstva», Beograd, 1976.

16. Hwang, P., Nilsson, B.: Razvojna psihologija, Sarajevo, 2000.

17. Ingliš H.B., Ingliš A.C.: Obuhvatni rečnik psiholoških $i$ psihoanalitičkih pojmova, Beograd, 1972.

18. Juul, J.: Vaše kompetentno dijete, «Educa», Zagreb, 1995. 
19. Košiček, M., Košiček, T.: I vaše dijete je ličnost, «»Panorama», Zagreb, 1968.

20. Kreč, D., Kračfild, R. S., Balaki, I.L.: Elementi psihologije, «Naučna knjiga», Beograd, 1980.

21. Kuburić, Z.: Porodica i psihičko zdravlje djece, «Čigoja štampa», Beograd, 2001.

22. Mandić, P., Radovanović I., Mandić D.: Uvod u opštu informatičku pedagogiju, Učiteljski fakultet, Beograd, 2000.

23. Pašalić - Kreso, A.: Koordinate obiteljskog odgoja, «Jež», Sarajevo, 2004.

24. Pregrad, J. (ured.): Stres, trauma, oporavak, «D.P.P.», Zagreb, 1996.

25. Smiljanić - Čolanović, V.: Sociometrija $i$ ispitivanje socijalne percepcije, «Zavod za udžbenike i nastavna sredstva Srbije», Beograd, 1973.

26. Tofler, A.: Treći talas, «Zenit», Beograd, 1983.

27. Toličić, I.: Psihički razvoj djeteta $i$ omladinca, «Pedagogija», br. 1., «Matica hrvatska», Zagreb, 1969.

28. Vasta, R., Haith, M.M., Miller, A. S.: Dječja psihologija, «Naklada Slap», Jastrebarsko, 1998. 


\section{FEHIM ROŠIĆ, SENIOR LECTURER}

\section{NOTION ABOUT ONESELF AS A PEDAGOGICAL CATEGORY - BASICS OF GUIDELINES AND MEANING}

\section{SUMMARY}

The picture about oneself, or notion about oneself as a special dimension of individuality is formed in a complex interactioin between individual and its community during the growth and forming of the personality. In defining or determining notion of oneself during the development of theoretical thought we can note two different approaches: traditional, which differs existential and empirical aspect of this notion and contemporary, which defines this notion as a system of three mutually connecetd processes: self - awareness, self evaluation and self-regulation. Notion of oneself is closely related with perception and self - perception which means, experiencing relation towards individual and experiencing oneslf.

Considering that the notion of oneself seriously impacts complete functioning of individual and that it is developed and formed during a complex process of mutual interactions and impact of different educational factors, this notion has a very important pedagogical dimension and meaning beside its psychological meaning.

Key words: notion of oneself, existential aspect, empirical aspect, self - awareness, self - evaluation, self - regulation, perception, self pereption, communication, fields of communication. 
الدكتور فهيم روشيتش

\section{فئة "إدر الك الذات" التربوية - المعنى والتوجهات الأساسية}

الملخص

في تفاعل معقد بين الثخص ومحيطه، من خلال عملية التتمية وبناء الثخصية، يتم تتمية وتكوين الصورة عن الذات، كبُعد متميز من الخاصية. في تحديد وتعريف عملية "إدر الك الذات" ومن خلال تتمية الفكر النظري يمكن ملاحظة اتجاهين: أحدهما تقليدي يفرق بين الجانب الوجودي و التجريبي لهذا الإدر الك، والآخر معاصر يعرّق إدر الك الذات

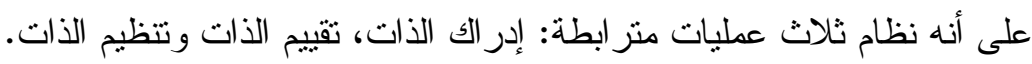

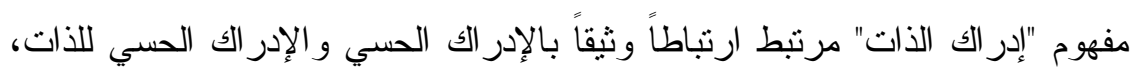
أي الشعور بعلاقة الآخرين تجاهه و الشعور بذاته.

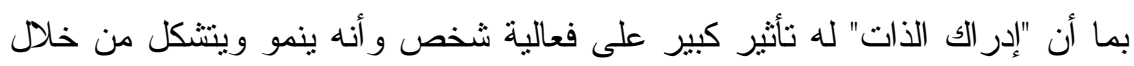

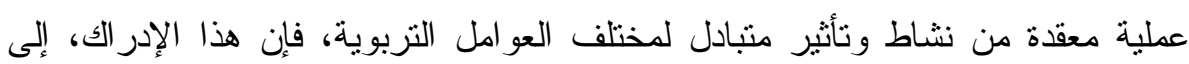

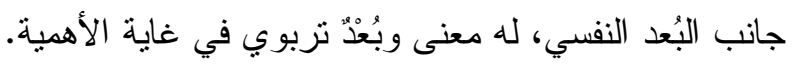

